\title{
Effects of Cotton Price on China's Cotton Import and the Analysis of
}

\author{
Marginal Import Effects \\ Jingzhou Wei ${ }^{*}$, Weizhong Liu \\ School of Economics and Business, Xinjiang Agriculture University, Urumqi, China \\ *Corresponding author: Jingzhou Wei, Doctoral students, 870826499@qq.com
}

\begin{abstract}
Since the reform of cotton circulation system, the contradiction between supply and demand of domestic cotton is more prominent, the fluctuation of China's cotton imports is intense. In order to analyze the internal mechanism of the quantity fluctuation of cotton import in china and the impact of cotton price (the international cotton price, the China's cotton price) on China's cotton imports, this paper build supply and demand balance equation, and derived the theoretical relationship between cotton price (the international cotton price, the China's cotton price) and China's cotton import. In order to verify the derivation of the theoretical relationship, we calculate the marginal effect of China's cotton import on the special value of the cotton price (the international cotton price, the China's cotton price) in this paper, and analyze the relationship between the cotton price and the China's cotton imports through the calculation of the marginal effect.The main analysis results are as follows: the decrease of negative effect of the international cotton price on the China's cotton import is conducive to promote the balance of supply and demand in China's cotton market, on the contrary, it is not conducive to promote the balance of supply and demand in China's cotton market.
\end{abstract}

Key words: China's cotton import; price shocks; equilibrium decision

\section{Introduction}

During the execution period of the temporary storage policy, China's cotton production has rapidly increased, the growing area has become larger and larger, and the country's reserves have increased dramatically, correspondingly, the cotton imports increased sharply, the price gap between domestic and foreign cotton market has expanded rapidly, many small and medium-sized textile enterprises shut down. Cotton target price reform pilot work carried out in Xinjiang in 2014, the target price is 19800 yuan / kg, the implementation of this policy led to a sharp decline in the market price of cotton, domestic and foreign cotton price gap became smaller, cotton imports fell rapidly etc.

There is a strong correlation between cotton price and cotton imports in china, most studies focus on the impact of international cotton prices on China's cotton imports, the impact of China's cotton price on China's cotton imports is lack of study. The general framework for the cotton price model is based on the theory of competitive markets, this article is no exception. Under the assumption of perfect competition, in this paper, the difference equation is constructed to explain the theoretical relationship between domestic and international cotton price and Chinese cotton imports, and this paper also construct a marginal effect model to verify the above relationships. The earlier models for cotton (Meyer ${ }^{5}, 1998$; Goreux et $\mathrm{al}^{3}$., 2007; Olga Isengildina -Massa and Stephen MacDonald ${ }^{6}$, 2009), wheat (Westcott and 
Hoffman $^{11}$,1999), corn (Van Meir ${ }^{9}$, 1983; Westcott and Hoffman ${ }^{11}$, 1999), and soybeans(Plato and Chambers ${ }^{7}, 2004$; Goodwin et $\mathrm{a}^{11}$., 2005) are very useful to the formation of this article.

\section{Empirical Analysis And Discussion}

\subsection{Data Description}

In order to make an empirical analysis, In this paper, we use the marginal effect analysis method to make an empirical analysis of the monthly cotton imports and domestic cotton price and foreign cotton price data from August 2005 to September 2015(China's cotton exports are very few in this period, so we use China's cotton imports instead of China's net imports of cotton), both domestic and international cotton prices selected the monthly price of three-level cotton, and the international cotton prices use FC INDEX M price index, and combined with the exchange rate of RMB against the U.S. dollar, inflation to adjust the price index of cotton.

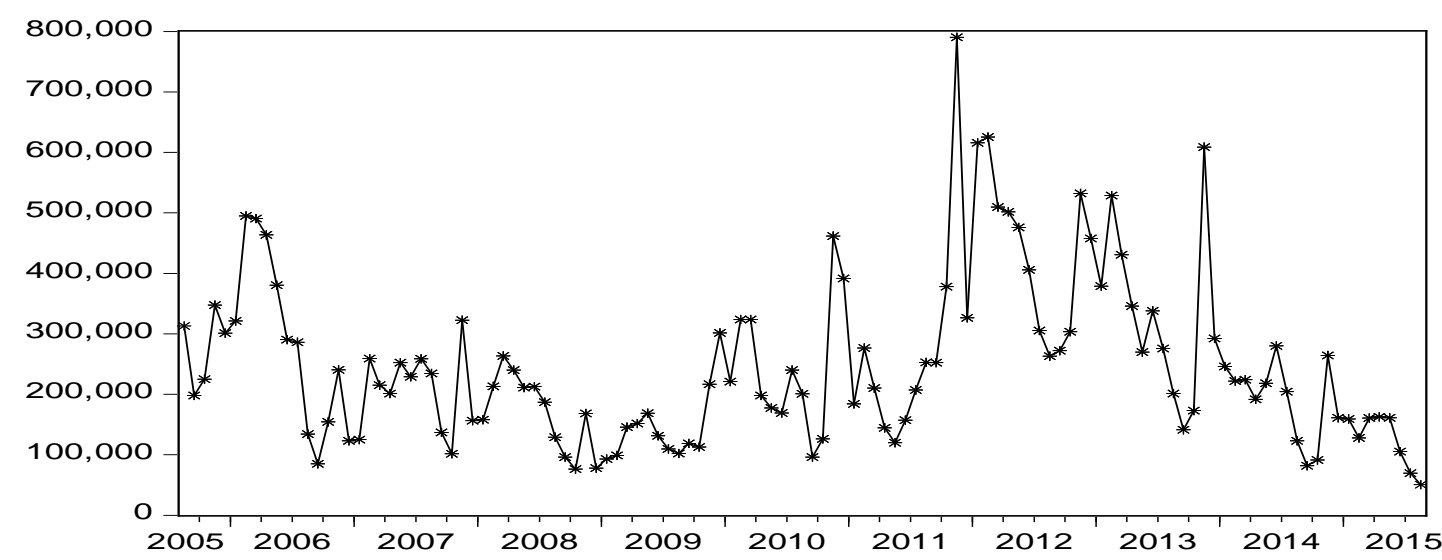

Figure 1- China's cotton import (unit: ton)

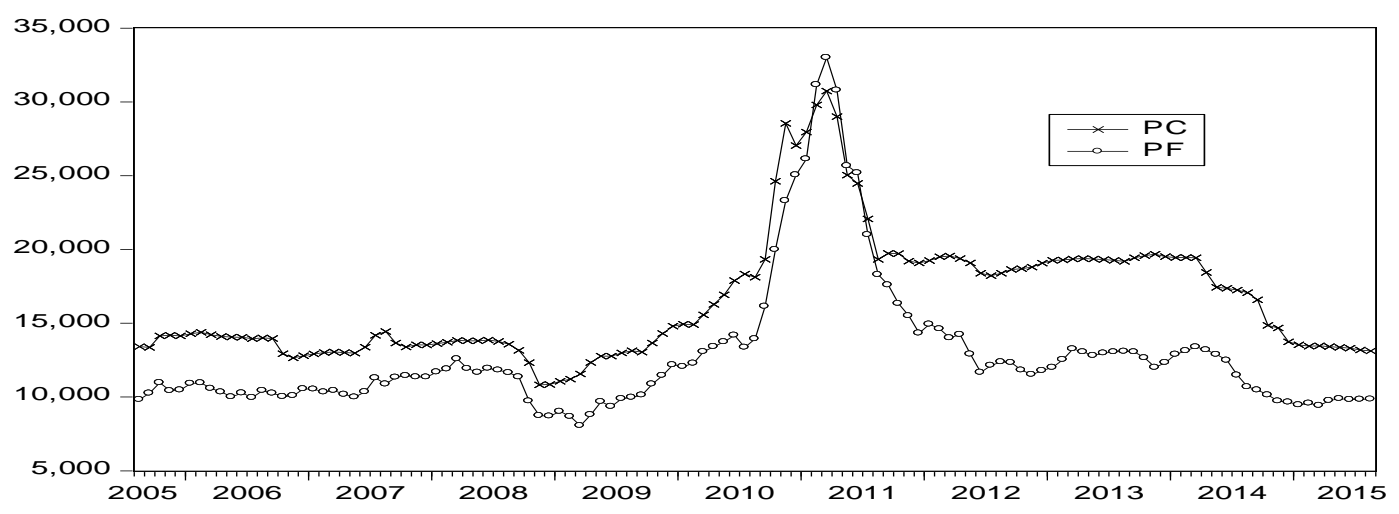

Figure 2 -Domestic and Foreign cotton price(unit: yuan / ton)

Under the influence of the target price mechanism, domestic cotton market prices fell down quickly, the linkage between domestic and international cotton price increase, domestic and foreign cotton market is more closely linked. As can be seen from Figure 1 and Figure 2, due to the temporary storage policy implementation, China's cotton imports remain high from 2011 to 2013, the gap between domestic and foreign cotton price expansion rapidly, and domestic cotton price far higher than international price. Target Price Reform Pilot Work carried out in Xinjiang in September 2014, the implementation of this policy has great 
influence on domestic cotton price, domestic cotton price fell rapidly, domestic and international cotton price gap decreased rapidly, under the 1\% tariff FC INDEX M price index was 11388 yuan / ton in September 2015, and the domestic 3128B cotton price was 13062 yuan / ton at the same time.

\subsection{Model framework}

Through the theoretical analysis of this paper, we can see that the marginal value of domestic cotton price and international cotton price to China's cotton imports is a key indicator of the balance between supply and demand in China's cotton market. In order to measure the marginal effect, this paper uses the calculus method to calculate AME (Average Marginal Effect), MEM (Marginal effect at the Mean), MER (Marginal Effect at the Representative value), $\mathrm{ME}$ is a local effect, it is commonly used to measure the influence of the unit change of $x_{i}$ on the conditional mean of $\mathrm{y}$, in a continuous explanatory variable, the ME value of the n-th explanatory variable is:

$$
M E_{i}=\frac{\partial E\left(y \mid X=X^{*}\right)}{\partial x_{i}}
$$

For Poisson regression model with $E(y \mid X)=\exp \left(X^{\prime} \eta\right)$, we can get $M E_{i}=\exp \left(X^{\prime} \eta\right) \eta_{i}$. In the actual calculation process, the ME value is not only the response parameter $\eta_{i}$, but also changes with the change of $X^{*}$.

According to the above theoretical framework, Using PC, PF, IM said the domestic cotton price, international cotton price, China's cotton import; and use LNPC, LNPF and LNIM run the model. Therefore, the following models are established in this paper:

$$
M E_{i}=\frac{\partial E\left(L N I M \mid X=X^{*}\right)}{\partial x_{i}} \text {, and } X=\left[\begin{array}{l}
\ln p f \\
\ln p c
\end{array}\right]
$$

\subsection{Discussion}

In the process of empirical analysis, all variables taken logarithm, the marginal effect indicates that the percentage of the dependent variable changes while the independent variable changes $1 \%$.

Table 1-average marginal effect

\begin{tabular}{lcccccc}
\hline variable & AME & Standard error & $\mathrm{Z}$ statistic & $\mathrm{P}>|\mathrm{Z}|$ & \multicolumn{2}{c}{ 95\% confidence intervals } \\
\hline $\ln \mathrm{PF}$ & -1.186331 & 0.3346589 & -3.54 & 0 & -1.84225 & -0.5304116 \\
$\ln \mathrm{PC}$ & 2.181958 & 0.3914286 & 5.57 & 0 & 1.414773 & 2.949144 \\
\hline
\end{tabular}

From the table 1 , domestic cotton prices increased by 1 percentage points, China's cotton imports will increase by 2.18 percentage points, that indicate that the increase of China's cotton market price will promote the increase of China's cotton import; international cotton price increased by 1 percentage points, it will make China's cotton import fell by 1.18 
percentage points, this shows that the increase of international cotton price will reduce the volume of China's cotton import. As can be seen from such a basic analysis, by comparing the absolute value, the impact of China's cotton price on China's cotton import is higher than the impact of the international cotton price on China's cotton import, that is to say, the Increasing effect of China's cotton price on China's cotton import is stronger than the reducing effect of international cotton price on China's cotton import.

Table 2-Marginal effect at the Mean

\begin{tabular}{|c|c|c|c|c|c|c|c|c|}
\hline & variable & MEM & $\begin{array}{l}\text { Standard } \\
\text { error }\end{array}$ & Z statistic & $\mathrm{P}>|\mathrm{Z}|$ & $95 \%$ con & ence intervals & $\begin{array}{l}\text { Average price } \\
\text { (yuan / ton) }\end{array}$ \\
\hline $\begin{array}{l}\text { Average value of } \\
\text { import (ton) }\end{array}$ & $\ln P F$ & -1.18608 & 0.33455 & -3.55 & 0 & -1.84178 & -0.53038 & $P F=12794.44$ \\
\hline $\mathrm{IM}=247215.3$ & $\ln P C$ & 2.181494 & 0.391222 & 5.58 & 0 & 1.41471 & 2.94827 & $\mathrm{PC}=16507.83$ \\
\hline
\end{tabular}

As can be seen from table 2, China's cotton average price changes $1 \%$, it will make China's cotton average import quantity change $2.18 \%$; international cotton average price changes $1 \%$, it will make the average quantity of China's cotton imports change $1.18 \%$. Further shows that, from the average level, the impact of China's cotton price on China's cotton import is stronger than the international price on China's cotton import.

For further analysis, the marginal effects of several representative values are solved in this paper, respectively, the minimum and maximum values of China's cotton import, the minimum and maximum value of domestic cotton price, the minimum value and maximum value of the international cotton price, the results are shown in Table 3.

Table 3-Marginal Effect at the Representative value

\begin{tabular}{|c|c|c|c|c|c|c|c|c|}
\hline Representative Value & variable & MER & Standard error & Z statistic & $\mathrm{P}>|\mathrm{Z}|$ & \multicolumn{2}{|c|}{ 95\% confidence intervals } & price \\
\hline IM(MIN)(TON) & $\ln P F$ & -1.168414 & 0.3297703 & -3.54 & 0 & -1.814752 & -0.5220763 & $\mathrm{PF}=9861.4512$ \\
\hline $\mathrm{IM}=50600.00$ & $\ln \mathrm{PC}$ & 2.149005 & 0.3829088 & 5.61 & 0 & 1.398518 & 2.899492 & $\mathrm{PC}=13116$ \\
\hline IM(MAX) (TON) & $\ln P F$ & -1.196816 & 0.3359775 & -3.56 & 0 & -1.85532 & -0.5383123 & $P F=15504.125$ \\
\hline $\mathrm{IM}=790402.06$ & $\ln \mathrm{PC}$ & 2.201243 & 0.394747 & 5.58 & 0 & 1.427553 & 2.974933 & $\mathrm{PC}=19201$ \\
\hline PF(MIN) (yuan / ton) & $\ln P F$ & -1.165167 & 0.331155 & -3.52 & 0 & -1.814219 & -0.5161152 & $P F=8050.9258$ \\
\hline IM=145559.92 元/吨 & $\ln P C$ & 2.143033 & 0.383925 & 5.58 & 0 & 1.390553 & 2.895512 & $\mathrm{PC}=11563.91$ \\
\hline $\begin{array}{l}\text { PF(MAX),PC(MAX) } \\
\text { (yuan / ton) }\end{array}$ & $\ln P F$ & -1.20958 & 0.3310019 & -3.65 & 0 & -1.858332 & -0.5608282 & $P F=32998.348$ \\
\hline $\mathrm{IM}=210453.16$ & $\ln \mathrm{PC}$ & 2.224719 & 0.3923593 & 5.67 & 0 & 1.455709 & 2.993729 & $\mathrm{PC}=30732.779$ \\
\hline PC(MIN) (yuan / ton) & $\ln P F$ & -1.142591 & 0.3200862 & -3.57 & 0 & -1.769948 & -0.5152332 & $\mathrm{PF}=8737.8193$ \\
\hline $\mathrm{IM}=168433.11$ & $\ln P C$ & 2.101509 & 0.3678702 & 5.71 & 0 & 1.380497 & 2.822521 & $P C=10830.05$ \\
\hline
\end{tabular}

Through the comparative analysis of the marginal effects of each representative value, we find that the IM(MAX) and PF(MAX) occurred in the temporary storage policy period, and at the two special data samples, the MER(lnPC) values were all above 2.20, higher than other representative value; $\mathrm{MER}(\ln P F)$ is close to -1.20 at the maximum value of import, the MER(lnPF) is smaller at the PF(MAX), its value is -1.20958 ; both domestic and international 
cotton price were at the highest point at the same time. During the implementation of temporary storage policy, this policy has led to the PC increased rapidly, and the IM also increased rapidly, the negative marginal effect of PF on IM became larger, domestic cotton supply and demand imbalance intensified by the policy.

In the data sample, the IM(MIN) is the data of September 2015, the MER(lnPC) became smaller at the sample point, that indicate the negative marginal effect of PF on IM was becoming smaller, during this period, the target price policy began to implement, this policy led to the quantity of IM reduce rapidly, and the PC value decreased rapidly, the balance of domestic cotton market has been enhanced, and it also further verifies the theoretical analysis of the previous paper.

Although the PC(MIN) and PF(MIN) were not in the same period, but the difference between the PC(MIN) and PF(MIN) is only four months, PC(MIN) appeared in November 2008,and $\mathrm{PF}(\mathrm{MIN})$ appeared in March 2009. The value of MER(lnPC) at the minimum value of PC is less than the value of MER(lnPC) at the minimum value of PF, and the MER(lnPF) is just on the contrary, the reducing effect of PC decrease on IM is stronger than the promotion effect of PF decrease on IM.

\section{Conclusion}

To sum up, this paper can draw a very clear conclusion: the decrease of negative effect of international cotton price on China's cotton import is conducive to promote the balance of China's cotton market supply and demand, on the contrary, it is not conducive to the balance of China's cotton market supply and demand.

Therefore, with the speed-up of the cotton market-oriented reform in China, good market price transmission mechanism will be conducive to the healthy development of China's cotton market, it will also make the quantity of China's cotton import return to a reasonable level.

\section{Acknowledgements}

This work was supported by National Social Science Fund Project of China, Project number: 15CMZ042.

\section{References}

1. J.N. Ferris, Agricultural Prices and Commodity Market Analysis, Michigan State University Press,2005.

2. B.K. Goodwin , R. Schnepf, and E. Dohlman. "Modelling soybean prices in a changing policy environment,” Applied Economics, 37: 253-263,2005.

3. L. Goreux , A. Plastina, A. Gruere, and Y. Cao. "The New ICAC Cotton Price Forecasting Model.” Cotton: Review of the World Situation, ICAC, July-August 2007.

4. L. Meyer, S. MacDonald, and R. Skinner. ,Cotton and Wool Outlook, Outlook Report No. CWS-08a, U.S. Department of Agriculture, 2008, Economic Research Service.http://usda.mannlib.cornell.edu/usda/ers/CWS//2000s/2008/CWS-03-12-2008 .pdf 
5. L.A. Meyer, Factors Affecting the U.S. Farm Price of Upland Cotton, Cotton and Wool Situation and Outlook, U.S. Department of Agriculture, CWS-1998, Economic Research Service. http://www.ers. usda.gov/briefing/ cotton/pdf /cws1998CottonFarmPrice.pdf

6. O. Isengildina-Massa and S. MacDonald, U.S. Cotton Prices and the World Cotton Market Forecasting and Structural Change, Economic research report (United States. Dept. of Agriculture. Economic Research Service); no. 80, 2009, United States. Dept. of Agriculture. Economic Research Service 1

7. G. Plato, and W. Chambers. How Does Structural Change in the Global Soybean Market Affect the U.S. Price? OCS-04D-01, U.S. Department of Agriculture, 2004 Economic Research Service. http://www.ers.usda.gov/ publications/OCS/APR04/ OCS04D01/OCS04D01.pdf

8. U.S. Department of Agriculture Agricultural Marketing Service, Cotton Program, Cotton Quality Annual Report, Vol. 81, No. 8,2008.

9. L.W. V. Meir, Relationships among Ending Stocks, Prices, and Loan Rates for Corn. Feed Outlook and Situation Report, FdS-290, U.S.Department of Agriculture, Economic Research Service,1983.

10. D.Wang, and W.G. Tomek, "Commodity Prices and Unit Root Tests," American Journal of Agricultural Economics, 89(4): 873-889,2007.

11. P.C. Westcott, and L.A. Hoffman, 1999. Price Determination for Corn and Wheat: The Role of Market Factors and Government Programs. Technical Bulletin No. 1878. U.S. Department of Agriculture, Economic Research Service. http://www.ers.usda.gov/ publications/tb1878/tb1878.pdf 